\title{
The effect of prepartum feeding and lying space on metabolic health and immune function
}

\author{
Cynthia L. Miltenburg, ${ }^{*}$ Todd F. Duffield, ${ }^{*}$ Dorothee Bienzle, $†$ Elizabeth L. Scholtz, ${ }^{*}$ and Stephen J. LeBlanc ${ }^{* 1}$ \\ *Department of Population Medicine, and \\ †Department of Pathobiology, University of Guelph, Guelph, Ontario, Canada N1G 2W1
}

\begin{abstract}
The determinants of metabolic and reproductive health disorders in the peripartum period and the degree to which feeding and lying space and management can influence health are only partially understood. The objective of this randomized controlled study was to determine whether providing noncompetitive feeding and lying access in the close-up dry period improves health and immune function. Forty-eight Holstein cows of all parities were randomly assigned to a treatment group of 6 to 10 cows in 1 pen with either $80 \%$ cows to stalls and $90 \mathrm{~cm}$ of feeding space per cow (understocked) or $120 \%$ stocking density and $45 \mathrm{~cm}$ of feeding space per cow (overstocked) for $3 \mathrm{wk}$ before expected calving. All cows wore electronic data loggers to monitor daily standing and lying time. Video recordings representing d 7 to 9 after group formation were reviewed, and a competition index (C_Ind) was calculated for each cow by dividing the number of times a cow displaced another as an actor by its total number of actor and reactor displacements. Cows were categorized as high success (C_Ind $\geq 0.6)$, moderate success $(0.4 \leq$ C_Ind $<0.6)$, or low success $($ C_Ind $<0.4)$. Weekly blood samples measured nonesterified fatty acids, $\beta$-hydroxybutyrate, calcium, glucose, albumin, aspartate aminotransferase, bilirubin, haptoglobin, insulin, and insulin-like growth factor- 1 from $3 \mathrm{wk}$ before to 5 wk after calving. Measures of innate immune function (neutrophil phagocytosis and oxidative burst) were assessed at $-2,-1,1,2,3$, and 5 wk relative to calving. Liver biopsies were collected at wk 1 and 3 . Cows in the understocked group spent significantly more time per day lying; the back-transformed least squares means and $95 \%$ confidence interval were $14.8 \mathrm{~h}(13.9-15.6)$ versus $12.8 \mathrm{~h}$ (12.0-13.7). Controlling for parity, there was no difference between treatments in $\beta$-hydroxybutyrate,
\end{abstract}

Received July 11, 2017.

Accepted January 26, 2018

${ }^{1}$ Corresponding author: sleblanc@uoguelph.ca nonesterified fatty acids, glucose, insulin, insulin-like growth factor 1, aspartate aminotransferase, bilirubin, or haptoglobin concentrations. Throughout the study, cows in the understocked treatment had higher mean calcium and tended to have higher albumin and at $3 \mathrm{wk}$ after calving tended to have lower mean liver triacylglycerol content. Overall, there was no treatment effect on phagocytosis, but cows with a higher C_Ind in the understocked treatment group had greater oxidative burst function. There was no effect of treatment on endometritis. Despite increased competition and lower lying time, the expected harmful effects of crowding and competition on metabolic indicators and innate immune function were mostly not observed. Although this does not refute the importance of access to feeding and lying space, these results indicate that metabolic and reproductive health is more complex than can be explained solely by exposure to what are understood to be best practices for space allowances.

Key words: transition cow, grouping strategy, immune parameter

\section{INTRODUCTION}

The peripartum period in dairy cows is characterized by a period of negative energy balance, diminished DMI, insulin resistance, lipolysis, and weight loss of varying severity (Goff and Horst, 1997; De Koster and Opsomer, 2013). Furthermore, diminished immune function typifies the peripartum period, a time when the majority of cows have bacterial contamination of the uterus that must be promptly eliminated (Sheldon et al., 2002). The innate immune system, specifically neutrophils as the first responders, is the primary means of cellular defense against bacterial colonization in the uterus. Impairment of neutrophil function has been documented beginning 2 wk before calving, reaching a nadir $1 \mathrm{wk}$ postpartum with slow recovery in the early weeks of lactation (Kehrli et al., 1989). Mitigating this immune suppression would be auspicious as it contributes to common production-limiting diseases important to animal welfare and profitability. 
Differences in innate immune function in the weeks ahead of calving have been recognized in several reproductive diseases. Metritis and endometritis have been associated with reduced neutrophil migration, phagocytosis, and oxidative burst function (Hammon et al., 2006) and reduced tumor necrosis factor $\alpha$, a proinflammatory mediator prepartum (Kim et al., 2005). These changes are present weeks before disease becomes manifest, coincident with the onset of insulin resistance and lipolysis. Cows in greater negative energy balance as measured by diminished DMI, higher nonesterified fatty acids (NEFA), and higher BHB and in particular those that go on to have metritis or endometritis have more pronounced impairment of at least some immune functions (Hammon et al., 2006; Galvão et al., 2010). High NEFA concentrations are a risk factor for ketosis and fatty liver and may have direct effects on neutrophil function as demonstrated in vitro by Scalia et al. (2006). Despite the emerging understanding of these relationships, among cows with similar nutrition and management it is unclear what determines the incidence of metabolic and reproductive disease.

An environment that limits DMI and lying time may have enduring effects on transition cow health. Proudfoot et al. (2009) demonstrated that with increased competition in transition pens, displacements at the feed bunk increased and cows ate less in the week before calving and spent more time standing in the week after calving. Many prepartum pens do not have a stable group structure, and additions may be weekly or more frequently. After regrouping, lactating dairy cows moved to a new pen had reduced resting time and feed intake and more displacements from the feed bunk (von Keyserlingk et al., 2008). Cook and Nordlund (2004) have suggested that weekly additions to close-up pens result in similar disruption of social interactions among prepartum cows. The relationships among cow grouping, group size, bunk space, and competition for feed have been reviewed with the recommendation that bunk space not be limited to avoid DMI reductions (Grant and Albright, 2001). Huzzey et al. (2007) found that cows with severe metritis ate 2 to $6 \mathrm{~kg}$ of DM less than healthy cows in the 2 to 3 wk before clinical signs of disease. Lower feed intake prepartum is associated with increased NEFA and hepatic lipid accumulation (Grummer, 1993). Whether impairment of immune function or reproductive disease risk can be influenced through management has not been well tested despite the recognized associations between a competitive environment and DMI. Two studies have looked at prepartum stocking density in Jersey cows previously.
A stable prepartum group with no further additions during the close-up period compared with a prepartum pen with weekly additions to maintain stocking density (100\% of stalls and $91.6 \%$ of headlocks) did not affect NEFA or BHB concentrations, retained placenta, metritis, or the percentage of neutrophils positive for phagocytosis or oxidative burst (Silva et al., 2013a,b). A second study that examined stocking pens at $80 \%$ versus $100 \%$ headlock stocking density and $86 \%$ versus $109 \%$ stalls found that treatment did not affect NEFA or BHB concentrations, retained placenta, metritis, or purulent vaginal discharge (Silva et al., 2014).

The objective of this study was to test whether providing noncompetitive access to feeding and lying modifies metabolic health and immune function. A secondary objective was to determine whether differences in metabolic health and immune function could be explained using a measure of social status in the group. The hypothesis was that providing greater feeding and lying space would reduce social stress and thereby improve measures of adaptation to negative energy balance and innate immune function.

\section{MATERIALS AND METHODS}

\section{Animals, Housing, and Management}

Twenty nulliparous and 28 parous (total $\mathrm{n}=48$, parity $2.0 \pm 1.2$ ) Holstein dairy cows housed in prepartum groups in a freestall facility at the former University of Guelph Dairy Research Centre (Guelph, ON, Canada) were enrolled in this study. Cows were managed according to the guidelines set by the Dairy Farmers of Canada and the National Farm Animal Care Council (DFC-NFACC, 2009), and the animal utilization protocol was approved by the University of Guelph Animal Care Committee. Cows were enrolled in the study 21 to $28 \mathrm{~d}$ before expected calving date and monitored until 5 wk after calving, from October 2012 to October 2013. Weeks were corrected to actual calving date. Groups consisted of 6 to 10 cows depending on the availability of calvings at the farm. Prior to group formation and after calving, cows were housed individually in tiestalls. The precalving diet was a controlled-energy TMR diet $\left(\mathrm{NE}_{\mathrm{L}}=1.37 \mathrm{Mcal} / \mathrm{kg}\right.$ of $\left.\mathrm{DM}\right)$ delivered once daily at 0600. After calving, all cows were fed a TMR ration 3 times per day $(0900,1300$, and $1500 \mathrm{~h}$ ) and were milked twice daily $(0530$ and $1600 \mathrm{~h})$. The diets fed were identical between treatment groups pre- and postpartum (Table 1). A sample size of 20 cows per group was planned based on a difference of 15 units $(\mathrm{SD}=16)$ between treatments for the percentage of cells activated 
Table 1. Composition of feed and nutrient analysis for prepartum ( $\mathrm{d}-24 \pm 3$ to 0 ) and postpartum (d 1 to 35) diets for 48 Holstein cows randomly assigned to be understocked ( $80 \%$ cows to stalls and $90 \mathrm{~cm}$ of feeding space per cow) or overstocked ( $120 \%$ cows to stalls and $45 \mathrm{~cm}$ of feeding space per cow) for 21 to $28 \mathrm{~d}$ prepartum

\begin{tabular}{|c|c|c|}
\hline Item & Prepartum & Postpartum \\
\hline \multicolumn{3}{|l|}{ Ingredient (\%) } \\
\hline Straw & 29.2 & 3.8 \\
\hline Haylage & 4.8 & 26.9 \\
\hline Corn silage & 40.9 & 28.7 \\
\hline High-moisture corn & - & 24.4 \\
\hline Concentrate mix & 25.1 & 16.2 \\
\hline \multicolumn{3}{|c|}{ Composition of concentrate mix (based on $1,000 \mathrm{~kg}$ of mix) } \\
\hline Tri Pro Gold ${ }^{1}$ & 345.60 & 248.70 \\
\hline Wheat shorts & 294.53 & - \\
\hline Canola meal & 130.10 & - \\
\hline Soybean meal & 73.80 & 295.41 \\
\hline Hi Pro corn gluten meal ${ }^{2}$ & - & 187.20 \\
\hline Calcium carbonate & 51.70 & 42.60 \\
\hline Monocalcium phosphate & 23.60 & 41.60 \\
\hline Sodium sesquicarbonate & - & 29.60 \\
\hline Fish meal & - & 29.60 \\
\hline Yeast & 16.50 & 13.30 \\
\hline Tallow & 30.00 & 24.00 \\
\hline Molasses & - & 24.00 \\
\hline Fine salt & 10.10 & 26.10 \\
\hline DCAD positive potassium carbonate & - & 15.40 \\
\hline Vitamin E & 9.10 & - \\
\hline Magnesium oxide & 8.90 & 9.20 \\
\hline FFM Org Ruminant Micro ${ }^{3}$ & 4.68 & 6.52 \\
\hline Monensin & 0.44 & 0.36 \\
\hline Sel-Plex $2000^{4}$ & 0.41 & 0.17 \\
\hline Sulfur flour $99.5 \%$ & 0.41 & 1.10 \\
\hline Rovimix Biotin $20,000^{5}$ & 0.13 & - \\
\hline MetaSmart $^{6}$ & - & 5.14 \\
\hline \multicolumn{3}{|l|}{ Item (\% of DM unless otherwise indicated) } \\
\hline $\mathrm{DM}(\%)$ & 53.24 & 48.47 \\
\hline $\mathrm{NE}_{\mathrm{L}}(\mathrm{Mcal} / \mathrm{kg})$ & 1.37 & 1.57 \\
\hline $\mathrm{CP}$ & 13.53 & 16.74 \\
\hline $\mathrm{ADF}$ & 28.83 & 18.15 \\
\hline NDF & 48.02 & 32.02 \\
\hline Ash & 8.63 & 8.24 \\
\hline Calcium & 1.03 & 0.91 \\
\hline Phosphorus & 0.45 & 0.45 \\
\hline Magnesium & 0.39 & 0.30 \\
\hline Potassium & 1.08 & 1.2 \\
\hline Sulfur & 0.19 & 0.24 \\
\hline Sodium & 0.16 & 0.36 \\
\hline Chlorine & 0.50 & 0.54 \\
\hline DCAD (mEq/100 g) & 9.25 & \\
\hline
\end{tabular}

${ }^{1}$ Tri Pro Gold (Tri County Protein Corp, Winchester, ON, Canada): bypass soybean meal.

${ }^{2} \mathrm{Hi}$ Pro corn gluten meal (Ingredion Canada Inc., London, ON, Canada).

${ }^{3}$ FFM Org Ruminant Micro (Floradale Feed Mill, Floradale, ON, Canada): trace mineral and vitamin premix containing 5 organic microminerals (zinc, manganese, copper, cobalt, and selenium).

${ }^{4}$ Sel-plex 2000 (Alltech, Nicholasville, KY): organic selenium.

${ }^{5}$ Rovimix Biotin 20,000 (DSM, Heerlen, the Netherlands): water-soluble B vitamin $(20,000 \mu \mathrm{g} / \mathrm{kg})$.

${ }^{6}$ MetaSmart (Adisseo, Alpharetta, GA): rumen-protected methionine.

by phorbol myristate acetate in an oxidative burst assay or percentage of neutrophils that phagocytosed $\geq 1$ fluorescent bead, both evaluated by flow cytometry.

\section{Treatments}

Each group was randomly assigned to be understocked or overstocked. Understocked cows were housed at $80 \%$ stocking density (cows to stalls), and $90 \mathrm{~cm}$ of bunk space was provided for each cow in the group. Overstocked cows were housed at $120 \%$ stocking density with $45 \mathrm{~cm}$ of bunk space per cow. The facilities in the barn and the numbers of cows available at one time only allowed for sequential (rather than concurrent) treatment groups. Groups of 6 to 10 cows and heifers with expected calving dates with a range of $7 \mathrm{~d}$ 
were formed and moved together to the study pen 21 to $28 \mathrm{~d}$ before expected calving. Expected calving was calculated as $280 \mathrm{~d}$ after breeding date, and the mean number of days in the groups was 24.1 and 24.6 for understocked and overstocked, respectively. No animals were added to groups once formed. Cows were moved from the pen to an individual maternity box stall 1 to $2 \mathrm{~d}$ before expected calving and were monitored until 5 wk after calving in tiestalls. The minimum number of cows in a treatment at the end of a study group was 2 , at which time both remaining animals were moved to maternity pens. The same prepartum pen was used for all consecutive groups and was adjusted to the group assignment. As animals were removed from the pen at calving, and the stall number and bunk space were adjusted such that the stocking density in the understocked group ranged from 66 to $85 \%$ and the stocking density in the overstocked group ranged from 114 to $150 \%$. The pen used was a gated-off portion of a 2-row freestall pen (stalls measuring $132 \times 188 \mathrm{~cm}$ ) with alleys of rubberized concrete $(239 \times 343 \mathrm{~cm})$. The surface of each stall comprised a rubber-crumb-filled mattress (Pasture Mat, Promat Ltd., Seaforth, ON, Canada) that was covered daily with clean chopped straw. The feeding space was a feed rail without headlocks, and gates were used to change the space allotted depending on treatment and cow numbers.

Rumination Time. While housed in the prepartum experimental pen, all cows were fitted with automated rumination monitoring devices (HR-Tags, SCR Engineers Ltd., Netanya, IL) validated by Schirmann et al. (2009). Collars were applied to cows the day they entered the treatment pen and measured rumination time for the duration of time in the pen. Raw rumination data were amassed by an automatic reader and saved with the associated software. Outputs provided the rumination time per 2 -h interval, which were summed into a daily value.

Lying Behavior. Daily lying behavior was collected using a 3 -axis accelerometer (Hobo Pendant G Logger, Hoskin Scientific Ltd., Burnaby, BC, Canada). The accelerometers were secured on the right hind leg of the cow on the day of entry to the pen to assess lying behavior of the cow at 1-min intervals as validated by Ledgerwood et al. (2010). The device was removed when the cow was moved to the calving pen, and data were downloaded using Hoboware Lite (Onset Computer Corp., Bourne, MA) and compiled using SAS 9.4 (UBC AWP, 2013).

Social Behavior. Competitive behavior at the feed bunk was monitored by digital video surveillance (Panasonic camera WV-CP504 and lens WV-LZA61/2S, Panasonic Canada Inc., Mississauga, ON, Canada) con- nected to a recording system (GeoVision, UVS 1240E2, GeoVision Inc., USAVisionSys, Irvine, CA). Cows in the pen were marked with unique alphanumeric symbols using cow paint if the cows were predominantly white haired and hair dye if the cow was predominantly black haired. Competitive behavior was assessed over 3 consecutive days (d 7-9 after group formation) for cows that were feeding. To be considered feeding, the cow's neck collar had to be visible beyond the top rail on the feed alley side of the pen. A displacement was recorded when a cow's head (actor) made contact with another cow's head that was feeding (reactor) and the reactor completely withdrew its head from the feed bunk as a result of the interaction. Each cow was assigned a competition index (C_Ind) score to describe the proportion of successful displacements relative to overall interactions as previously described by Galindo and Broom (2000). The C_Ind was calculated as follows:

$$
\text { C_Ind }=\text { no. of times cow is actor }
$$

no. of times cow is actor + no. of times cow is reactor

Cows were categorized as low ranking (index $<0.4$ ), middle ranking (index 0.4-0.6), or high ranking (index $>0.6$ ). Video was reviewed by 2 individuals, and interobserver reliability was assessed using the raw score for total interactions $\left(\mathrm{R}^{2}=0.90\right)$. The daily time from delivery of fresh feed to first appearance at the feed bunk was also recorded for all cows in the pen utilizing the video of $d 7$ to 9 in the pen.

Blood Metabolites. On a weekly basis, with the first sample taken immediately before cows entered the treatment pen on the day of group assembly, whole blood was collected from the coccygeal vein or artery using a 20-gauge, 1-inch $(2.54 \mathrm{~cm})$ hypodermic needle into sterile glass vacuum blood collection tubes without anticoagulant (BD Vacutainer Precision Glide, Becton Dickinson, Franklin Lakes, NJ). In tandem, two 8.5$\mathrm{mL}$ vacuum tubes of blood were collected with the anticoagulant acid citrate dextrose (Vacutainer, Becton Dickinson) for neutrophil isolation at wk $-2,-1,1,2$, 3 , and 5. Blood with preservative was inverted gently 10 times to ensure mixing. All samples were placed on ice for transport, and within $3 \mathrm{~h}$ of sampling serum was harvested from whole blood without anticoagulant by centrifugation at $1,500 \times g$ for $15 \mathrm{~min}$. All serum was separated into 4 aliquots and stored at $-20^{\circ} \mathrm{C}$.

Serum from each week of enrollment as well as the day of calving was submitted to the Animal Health Laboratory, University of Guelph, for measurement of NEFA, BHB, total calcium, glucose, albumin, aspartate 
aminotransferase (AST), total bilirubin, and haptoglobin concentrations. Analysis was performed using an autochemistry analyzer (Cobas 6000 c 501, Roche Diagnostics, Indianapolis, IN). The NEFA and BHB concentrations were determined using Randox NEFA and Randox BHB kits (Randox Laboratories Canada Ltd., Mississauga, ON, Canada). The analytical sensitivity of both assays is $0.1 \mathrm{mmol} / \mathrm{L}$, and the intra-assay coefficients of variation were 4.3 and $2.5 \%$ for NEFA and $\mathrm{BHB}$, respectively. Total calcium concentration was measured using the Cobas Calcium Gen 2 kit (Roche Diagnostics, Indianapolis, IN). The analytical sensitivity of the calcium assay is $0.2 \mathrm{mmol} / \mathrm{L}$, and the intra-assay coefficient of variation was $2.2 \%$. Glucose concentrations were measured using the Roche GLUC3 kit (Roche Diagnostics). The analytical sensitivity of the glucose assay is $0.1 \mathrm{mmol} / \mathrm{L}$, and the intra-assay coefficient of variation was $1.13 \%$. Albumin concentrations were measured using Cobas ALB2 kit (Roche Diagnostics) with an analytical sensitivity of $2 \mathrm{~g} / \mathrm{L}$, and the intra-assay coefficient of variation was $1.9 \%$. Total bilirubin and AST concentrations were measured using Cobas BILTS and Cobas ASTL kits (Roche Diagnostics). The analytical sensitivity of the total bilirubin assay is $1.7 \mu \mathrm{mol} / \mathrm{L}$, and the intra-assay coefficient of variation was $3.2 \%$. The analytical sensitivity of the AST assay is $5 \mathrm{U} / \mathrm{L}$, and the intra-assay coefficient of variation was $1.9 \%$. Hemoglobin binding capacity was used to measure haptoglobin concentrations. A methemoglobin reagent was made on site according to the method described by Makimura and Suzuki (1982) and Skinner et al. (1991). The analytical sensitivity of the haptoglobin assay is $0.03 \mathrm{~g} / \mathrm{L}$, and the intra-assay coefficient of variation was $5.5 \%$.

The quantitative determination of insulin in bovine serum was performed in our laboratory using a bovine insulin ELISA (Mercodia AB, Uppsala, Sweden). The detection limit of the assay is $0.025 \mu \mathrm{g} / \mathrm{L}$, and the intra-assay and interassay coefficients of variation were 7.4 and $11.9 \%$, respectively. The quantitative determination of IGF-1 was performed using a human IGF-1 immunoassay (Quantikine ELISA, RnDSystems, Minneapolis, MN). The detection limit of the assay is 0.026 $\mu \mathrm{g} / \mathrm{L}$, and the intra-assay and interassay coefficients of variation were 7.1 and $8.4 \%$, respectively. The insulin and IGF-1 ELISA microplates were read with a spectrophotometer (EON, Biotek, Winooski, VT).

Glucose Tolerance Test. A simplified glucose tolerance test was performed $1 \mathrm{wk}$ before expected calving date using the procedure described by Matteo et al. (2009). An intravenous bolus of $0.25 \mathrm{~g}$ of dextrose $/ \mathrm{kg}$ of BW (dextrose 50\%, Vétquinol Canada Inc., Lavaltrie, QC, Canada) was given via jugular venipuncture over 2 min. Blood samples were collected immediately before the dextrose infusion from the jugular vein $(0 \mathrm{~min})$ and at 10 and 80 min after infusion from the coccygeal vein or artery for blood glucose and insulin concentrations. These tubes were immediately placed on ice. The ratio of blood glucose concentrations at $80 \mathrm{~min}$ to $0 \mathrm{~min}$ was calculated and examined at 2 cut points, 1.05 and 1.2, to assess insulin resistance per Matteo et al. (2009).

Neutrophil Isolation. Eight milliliters of whole blood with the anticoagulant acid citrate dextrose was diluted with $20 \mathrm{~mL}$ of $1 \times$ concentrated PBS at room temperature, overlaid on $8 \mathrm{~mL}$ of Ficoll-Paque PLUS (General Electric Healthcare Bio-Sciences AB, Uppsala, Sweden) at room temperature, and centrifuged at $700 \times g$ for $30 \mathrm{~min}$. The plasma and buffy coat were removed by pipette, and erythrocytes were lysed with 6 volumes of sterile cold water using gentle inversion. Three volumes of $3 \times$ concentrated PBS were added to re-establish osmolarity and centrifuged at $4^{\circ} \mathrm{C}$ at $500 \times$ $g$ for $10 \mathrm{~min}$. The supernatant was removed by pipette, and samples were washed and centrifuged again if visible hemoglobin remained in the cell pellet. Once free of hemoglobin, cell pellets were resuspended in $500 \mathrm{uL}$ of $1 \times$ PBS, and a hemocytometer chamber and trypan blue exclusion were used to assess cell concentration. The pelleted neutrophils were diluted to a concentration of $1 \times 10^{6} / \mathrm{mL}$ using $1 \times$ concentrated PBS with $10 \%$ filtered fetal bovine serum (Invitrogen, Burlington, ON, Canada).

Oxidative Burst Assay. In a flow cytometry tube (BD Biosciences, Bedford, MA), $2 \mu \mathrm{L}$ of $1 \mathrm{mM}$ 2',7'-dihydro-dichlorofluroscein-diacetate $\left(\mathbf{H}_{2} \mathbf{D C F D A}\right.$; Molecular Probes, Eugene, OR) was added to $200 \mu \mathrm{L}$ of the reconstituted neutrophils, and the tubes were incubated in the dark for $15 \mathrm{~min}$ at $37^{\circ} \mathrm{C}$ under gentle agitation. Subsequently, $200 \mu \mathrm{L}$ of $1 \times$ concentrated PBS with $10 \%$ FBS was added to control samples and $200 \mathrm{uL}$ of phorbol myristate acetate (PMA; SigmaAldrich, St. Louis, MO) diluted in PBS/FBS for a total of $25 \mathrm{ng} / \mathrm{mL}$ of PMA was added to stimulate oxidative burst in noncontrol samples. All tubes were incubated in darkness for a further 15 min at $37^{\circ} \mathrm{C}$ with gentle agitation and then placed on ice and protected from light until flow cytometry. The green cellular fluorescence of the $\mathrm{H}_{2}$ DCFDA was measured on a flow cytometer as described below.

Phagocytosis Assay. One volume of activated normal cow serum was produced for the full experiment using serum from 20 healthy lactating Holstein cows at the University of Guelph Dairy Research Centre. One hundred milligrams of Zymosan A from Saccharomyces cerevisiae (Sigma-Aldrich) was added per $10 \mathrm{~mL}$ of pooled serum, incubated at $37^{\circ} \mathrm{C}$ for 60 min under 
gentle rotation, and centrifuged at $2,500 \times g$ for 15 min. The serum was removed and stored at $-80^{\circ} \mathrm{C}$.

In a flow cytometry tube, $200 \mu \mathrm{L}$ of reconstituted neutrophils was incubated with $1 \times 10^{6}$ fluorescently labeled 1- $\mu \mathrm{m}$ beads (TransFluo-Spheres Fluorescent Microspheres, Molecular Probes) and $50 \mu \mathrm{L}$ of normal cow serum with Zymosan A for $30 \mathrm{~min}$ at $37^{\circ} \mathrm{C}$ in the dark. Each sample had a negative control of neutrophils incubated without fluorescent beads. Following incubation, cells were resuspended in flow buffer, placed on ice, and protected from light until phagocytosis of the fluorescent beads was measured on the flow cytometer.

Flow Cytometry Analysis. A flow cytometer (FACScan, Becton Dickinson) with Cell Quest software (Becton Dickinson) was used to measure oxidative burst and phagocytosis. Neutrophil fluorescence was identified on cytograms of forward versus side scatter, and a gate was placed around the neutrophil population. The $\mathrm{H}_{2} \mathrm{DCFDA}$ oxidation was measured at $530 \mathrm{~nm}$ and phagocytosis of fluorescent beads was measured at 645 $\mathrm{nm}$ on a $\log$ scale. The mean intensity of fluorescence for oxidative burst and phagocytosis was recorded by Cell Quest software. Samples were analyzed using FlowJo software (Tree Star, Ashland, OR). For each observation, the shift in the percentage of cells that underwent oxidative burst or phagocytosis was evaluated relative to the negative control. A gate was placed around $\geq 97 \%$ of samples without PMA for the oxidative burst analysis and samples without fluorescent beads for the phagocytosis analysis (negative controls). The difference between the negative control and the positive observation for the percentage of cells outside the negative control gate was used to express success of oxidative burst or phagocytosis.

Uterine Health Parameters. All cows were examined for vaginal discharge using a disposable vaginal speculum (JorVet Jorgensen Labs, Loveland, CO) at wk 3 and 5 after parturition. Discharge was scored according to the scoring system outlined in Sheldon et al. (2006). Subsequently, cervical and uterine cytology samples were collected to assess cervicitis and endometritis. Using a cytobrush (VWR CanLab, Mississauga, ON, Canada) and modified AI rod, 2 samples were obtained - the first from directly beyond the most caudal ring of the cervix and the second from the uterine body. As described in Dubuc et al. (2010), cytology slides were generated, stained, and examined for the number of neutrophils per 100 nucleated cells (neutrophil: epithelial cell ratio). Samples with $\geq 6 \%$ polymorphonuclear cells at cervical or endometrial cytology were classified as cervicitis or endometritis positive, respectively, at 5 wk postpartum.
BCS and Milk Yield. All cows were scored for body condition by a single observer on the day of group assembly at 3 wk before calving and at the last sample collection at 5 wh after calving using the scoring system described by Ferguson et al. (1994). Milk yield was recorded daily using milking parlor meters throughout the 5 wk postpartum.

Liver Biopsies. At wk 1 and 3 after calving, a liver biopsy was performed while cows were restrained in a standing chute. The biopsy was performed according to the procedure described in Mølgaard et al. (2012). An 8-mm-diameter trocar biopsy tool was used to collect approximately $2 \mathrm{~g}$ of liver tissue. All samples were immediately frozen in liquid nitrogen and stored at $-80^{\circ} \mathrm{C}$.

Tissue Triacylglycerol Concentration. Liver biopsies were analyzed for triacylglycerol (TAG) concentration at the Mammalian NutriPhysioGenomics laboratory, Department of Animal Sciences, University of Illinois (Urbana). A total of $50 \mathrm{mg}$ of tissue was first homogenized in $1.5 \mathrm{~mL}$ of PBS/10 $\mathrm{m} M$ EDTA using a hand-held homogenizer (Tissue-Tearor, BioSpec Products, Bartlesville, OK). Subsequently, $200 \mu \mathrm{L}$ of $0.1 \%$ green food coloring PBS-EDTA and $3 \mathrm{~mL}$ of isopropanol-hexane-water (80:20:2 vol/vol) were added to each sample, and the mixture was incubated covered with aluminum foil for $30 \mathrm{~min}$ at room temperature. One milliliter of hexane-diethyl ether (1:1) was then added to each sample followed by vortexing and incubation for $10 \mathrm{~min}$ at room temperature (protected from light). One milliliter of water was added to each sample to separate the lipid phase, and the mixture was vortexed. Samples were incubated and covered with aluminum foil for approximately $20 \mathrm{~min}$ at room temperature. The organic phase was then aspirated and placed into glass vials before evaporation under a stream of $\mathrm{N}$ gas. An 8-point TAG standard was prepared with Infinity TG reagent (cat no. 10010509, Cayman Chemicals, Ann Arbor, MI). Each sample was mixed with $540 \mu \mathrm{L}$ of Infinity TG reagent before vortexing. A total of $160 \mu \mathrm{L}$ of this sample mixture was pipetted into a flat-bottom 96-well plastic microplate. The plate was incubated for $15 \mathrm{~min}$ at $37^{\circ} \mathrm{C}$ before determining absorbance at 540 $\mathrm{nm}$ using a microplate reader. Concentration of TAG was calculated from the standard curve.

\section{Statistical Analysis}

All statistical analyses were performed in SAS (version 9.4, SAS Institute, Cary, NC) considering the cow as the experimental unit and experimental block offered as a random effect. The effects of treatment on 
each behavioral measure (lying time, rumination time, and feed bunk displacements) were modeled using linear mixed models (PROC MIXED) with the repeated measures statement. A logit transformation was used to normalize lying time. Daily lying and rumination times were adjusted to actual day of calving and were censored at d -2 once cows left the group pen and were moved to the maternity pen. Data before d -24 were excluded due to a lack of observations. Parity (set as 1,2 , and $\geq 3$ ) and body condition at enrollment (set as $\leq 3.5$ and $\geq 3.75$ ) were offered as covariates to all models. Interactions between treatment and each covariate were tested and retained where significant.

The effect of treatment group on the metabolic parameters (measured weekly) BHB, NEFA, glucose, insulin, IGF-1, calcium, AST, total bilirubin, albumin, and haptoglobin and the immune parameters oxidative burst and phagocytosis were modeled using linear mixed models (PROC MIXED) with the repeated measures statement. Haptoglobin, BHB, NEFA, liver TAG, oxidative burst, and phagocytosis were normalized using a log transformation. Parity and body condition at enrollment were offered as covariates to all models. Competition index was offered as a covariate to all metabolic and immune parameter models. Where significant as a covariate, the model including C_Ind is reported. All data with a log transformation were back transformed for ease of interpretation.

Descriptive statistics were generated using PROC FREQ and PROC MEANS in SAS. Any variable associated with the outcome at $P<0.2$ was offered to multivariable models. Variables were removed manually by backward stepwise elimination in order of highest $P$-value until only variables associated with the outcome remained $(P<0.1)$. With each variable removal, evidence of confounding was determined by a change in coefficient for treatment of $>20 \%$. Interactions between treatment group and each covariate were tested and retained where significant. For all models, the covariance error structure yielding the lowest Akaike information criterion value was used, choosing from autoregressive, heterogeneous, or Toeplitz.

Fisher's exact test was used to evaluate the probability of endometritis and cervicitis and the probability of being insulin resistant at 2 different cut points of the ratio of blood glucose concentrations at $80 \mathrm{~min}$ to $0 \mathrm{~min}$ following a glucose tolerance test. Area under the curve was calculated for insulin measured from each serum sample taken during the glucose tolerance test. Total area using the trapezoidal rule was calculated (Cardoso et al., 2013), log transformed to improve normality, and modeled using a linear mixed model (PROC MIXED).

Daily milk yield was collapsed into weekly means and modeled using a linear mixed model (PROC MIXED) with the repeated measures statement. Significance was reported for $P$-values $<0.05$, and tendencies were reported for $P$-values $<0.1$.

\section{RESULTS}

A total of 48 cows were enrolled in the study - 22 in the understocked group (9 primiparous and 13 multiparous) and 26 in the overstocked group (12 primiparous and 14 multiparous). There were too few cases of clinical disease to produce a meaningful analysis.

\section{Effect of Treatment on Measures of Behavior}

Over the $3 \mathrm{wk}$ in the prepartum pen, lying time averaged $13.6 \pm 2.7 \mathrm{~h} / \mathrm{d}$ among all cows. Cows in the understocked group spent significantly more time lying per day $(P=0.02)$, accounting for parity $(P<0.001)$ and days from calving $(P<0.001)$. The least squares means for the time spent lying were $14.8 \mathrm{~h}(95 \% \mathrm{CI}$ : 13.8-15.7) for understocked cows and $12.9 \mathrm{~h}$ (95\% CI: 12.1-13.8) for overstocked cows. First-parity animals spent less time lying than third-parity animals, and second-parity cows tended to spend less time lying than third-parity cows. The individual cow mean \pm standard deviation variation in daily lying time was $79 \pm 48 \mathrm{~min}$ for understocked cows and $98 \pm 38$ min for overstocked cows and did not differ between treatments $(P=0.14)$.

Over $3 \mathrm{~d}$ of continuous observation, the mean $( \pm \mathrm{SD})$ number of total interactions (actor + reactor interactions) at the feed bunk was $82( \pm 41)$ and $44( \pm 23)$ for overstocked and understocked cows, respectively. In a linear mixed model, there were fewer total interactions among understocked cows $(P=0.04)$, accounting for parity. Actor and reactor interactions were modeled independently considering treatment only. Cows in the overstocked group had a higher frequency of displacements from the feed bunk and were involved in almost twice the number of displacements $(41 \pm 6$ vs. $21 \pm 6 ; P=0.02)$. When added to the model, parity confounded this relationship such that the number of displacements did not differ between treatment groups $(P=0.28)$ accounting for parity $(P=0.06)$. Least squares means were $39 \pm 6$ for overstocked cows and 29 \pm 7 for understocked cows. Second-parity cows tended to participate in more actor interactions. For the total number of reactor interactions, removal of the parity covariate caused a change of $>20 \%$ in the coefficient for treatment, verifying that confounding was present. An analysis stratified by parity demonstrated that the effect was driven by crowded multiparous cows. Over $3 \mathrm{~d}$ of continuous observation, total reactor interactions did not differ significantly $(P=0.21)$ accounting for parity $(P=0.44)$. The least squares means were $38 \pm 6$ for 
the overstocked group and $25 \pm 7$ for the understocked group.

On d 7 to 9 after formation of treatment groups, there were no differences between treatment groups in the mean time to visit the feed bunk after fresh feed delivery (understocked: $18 \pm 31 \mathrm{~min}$; overstocked: 22 $\pm 61 \mathrm{~min} ; P=0.78$ ) or the proportion of cows that did not attend the feed bunk within 10 min after fresh feed delivery (understocked: 12\%; overstocked: 10\%; $P=0.84$ ). Daily rumination during the $3 \mathrm{wk}$ in the prepartum pen averaged $7.7 \pm 1.9 \mathrm{~h}$ for all cows. Rumination detectors were not functional for the first pen of cows; therefore, rumination was recorded from 16 understocked cows and 26 overstocked cows. There was no difference in rumination time between treatments $(P=0.18)$ accounting for days from calving. The least squares means of daily ruminating time accounting for days from calving were $7.2 \pm 0.3$ and $7.8 \pm 0.2 \mathrm{~h}$ for understocked and overstocked cows, respectively.

\section{Effect of Treatment on Metabolic Health}

There was no difference between treatment groups in concentrations of BHB, NEFA, glucose, insulin, IGF-1, AST, bilirubin, or haptoglobin in serum and no treatment $\times$ time interactions. These are described in Supplemental Figures S1 to S8 (https://doi.org/10 .3168/jds.2017-13481).

Serum albumin concentrations tended to be higher in the understocked cows throughout the study period ( $P$ $=0.06$ ) accounting for sampling week, parity, BCS at enrollment, treatment $\times$ week interaction $(P=0.06)$, and the random effect of experimental block (see Supplemental Figure S9; https://doi.org/10.3168/jds.2017 -13481). There was no effect of treatment when albumin was examined at individual sampling weeks $(P>$ $0.10)$. Cows in the overstocked group had significantly lower albumin at wk $-2,-1$, and 0 . First-parity cows had lower albumin, as did cows with a BCS $\geq 3.75$. The least squares means \pm standard error over 9 outcome measurements were $35.98 \pm 0.4$ for understocked cows and $34.52 \pm 0.36$ for overstocked cows.

Serum total calcium was significantly higher among the understocked cows $(P=0.03)$ accounting for sampling week, parity, and experimental block as a random effect (see Supplemental Figure S10; https://doi.org/ 10.3168/jds.2017-13481). Cows in third parity and greater had significantly lower calcium, and calcium was significantly lower at wk 0 and 1 . There was no treatment $\times$ week interaction. The least squares means \pm standard error over 9 outcome measurements were $2.37 \pm 0.02$ for understocked cows and $2.29 \pm 0.02$ for overstocked cows. Because approximately half of blood calcium is bound to albumin, albumin concentration was offered as a covariate. Serum total calcium did not differ between treatment groups $(P=0.40)$ accounting for week, parity, and albumin concentration.

The C_Ind of the cow and the C_Ind $\times$ treatment interaction were offered to all models as covariates. Competition index was retained in the models for glucose, insulin, IGF-1, and AST. All other covariates previously described remained in the models. Relative to high- $\mathrm{C}_{-}$ Ind cows $($ C_Ind $>0.6)$, low-C_Ind cows $($ C_Ind $<0.4)$ had lower insulin and IGF-1 concentrations $(P<0.01)$ and tended to have lower glucose concentrations $(P=$ 0.09). The moderate-C_Ind cows (C_Ind 0.4-0.6) had significantly lower AST than high-C_Ind cows.

\section{Effect of Treatment on Liver TAG}

Sufficient liver samples were collected from 30 cows at wk 1 (d 2-7 postpartum) and 29 cows from wk 3 (d 15-21 postpartum). In the first week the mean \pm standard deviation TAG content was $2.89 \pm 2.96 \%$ in the understocked treatment and $3.79 \pm 4.02 \%$ in the overstocked treatment; $17 \%$ of understocked cows and $28 \%$ of overstocked cows $(P=0.67)$ had TAG $>5 \%$, indicating at least moderate fatty liver. There was no significant difference in the log-transformed TAG content between treatment groups $(P=0.70)$. In the third week, the mean \pm standard deviation for TAG content was $2.85 \pm 3.27 \%$ in the understocked treatment and $5.43 \pm$ $5.63 \%$ in the overstocked treatment. Understocked cows tended to have lower log-transformed TAG content $(P$ $=0.09$ ) accounting for block as a random effect. At wk $3,14 \%$ of understocked cows and $43 \%$ of overstocked cows had TAG $>5 \%(P=0.21)$.

\section{Effect of Treatment on Indicators of Insulin Resistance}

The ratio of blood glucose concentrations at $80 \mathrm{~min}$ to $0 \mathrm{~min}$ from the modified glucose tolerance tests was examined at the cut points 1.05 and 1.2 , and cows above the cut point were defined as insulin resistant. There was no difference between understocked and overstocked cows for the proportion of cows above the cut point 1.05 (67 vs. $69 \% ; P=0.99$ ) or 1.2 (44 vs. $36 \% ; P=0.75)$. There was no significant difference in the area under the insulin curve from the $0-, 10-$, and 80 -min blood samples between treatment groups $(P=$ 0.17 ) accounting for parity.

\section{Effect of Treatment on Immune Function}

The results are depicted in Supplemental Figures S11 and S12 (https://doi.org/10.3168/jds.2017-13481). 
Log-transformed oxidative burst function did not differ between treatment groups $(P=0.69)$ accounting for sampling week and experimental block as a random effect. Least squares means were $23.7 \%$ (95\% CI: 7.0779.1) and $18.3 \%$ (95\% CI: 5.5-60.9) for understocked and overstocked cows, respectively. When C_Ind was offered as a covariate, there was a C_Ind level $\times$ treatment interaction $(P=0.01)$ such that oxidative burst function was greater among understocked cows with a moderate $(P<0.01)$ or high $(P<0.01)$ C_Ind compared with low-C_Ind understocked or overstocked cows. Predicted values for each treatment and C_Ind level are displayed in Figure 1. Log-transformed phagocytosis did not differ between treatment groups $(P=$ 0.87 ) accounting for sampling week, parity, treatment $\times$ week interaction $(P=0.003)$, and pen as a random effect. There was no effect of treatment when the logtransformed phagocytosis index was modeled at each sampling week $(P>0.17)$ accounting for parity and the random effect of pen. The log-transformed mean intensity of fluorescence for oxidative burst and phagocytosis did not differ between treatments $(P>0.72)$ accounting for sampling week, treatment $\times$ sampling week interaction, and pen as a random effect as well as parity in the mean intensity of fluorescence phagocytosis model.

\section{Effect of Treatment on Uterine Health}

At 5 wk postpartum, 3 of 46 available cows were diagnosed with purulent vaginal discharge by vaginoscopy. Concurrently, cervical cytology was collected from 44 cows, of which $14 \%(\mathrm{n}=6)$ were classified as having cervicitis. Endometrial cytology was collected from 43 cows, of which $33 \%(\mathrm{n}=14)$ were classified as having endometritis. No treatment effects were detected in the incidence of cervicitis $(P=0.68)$ or endometritis $(P=$ $0.10)$.

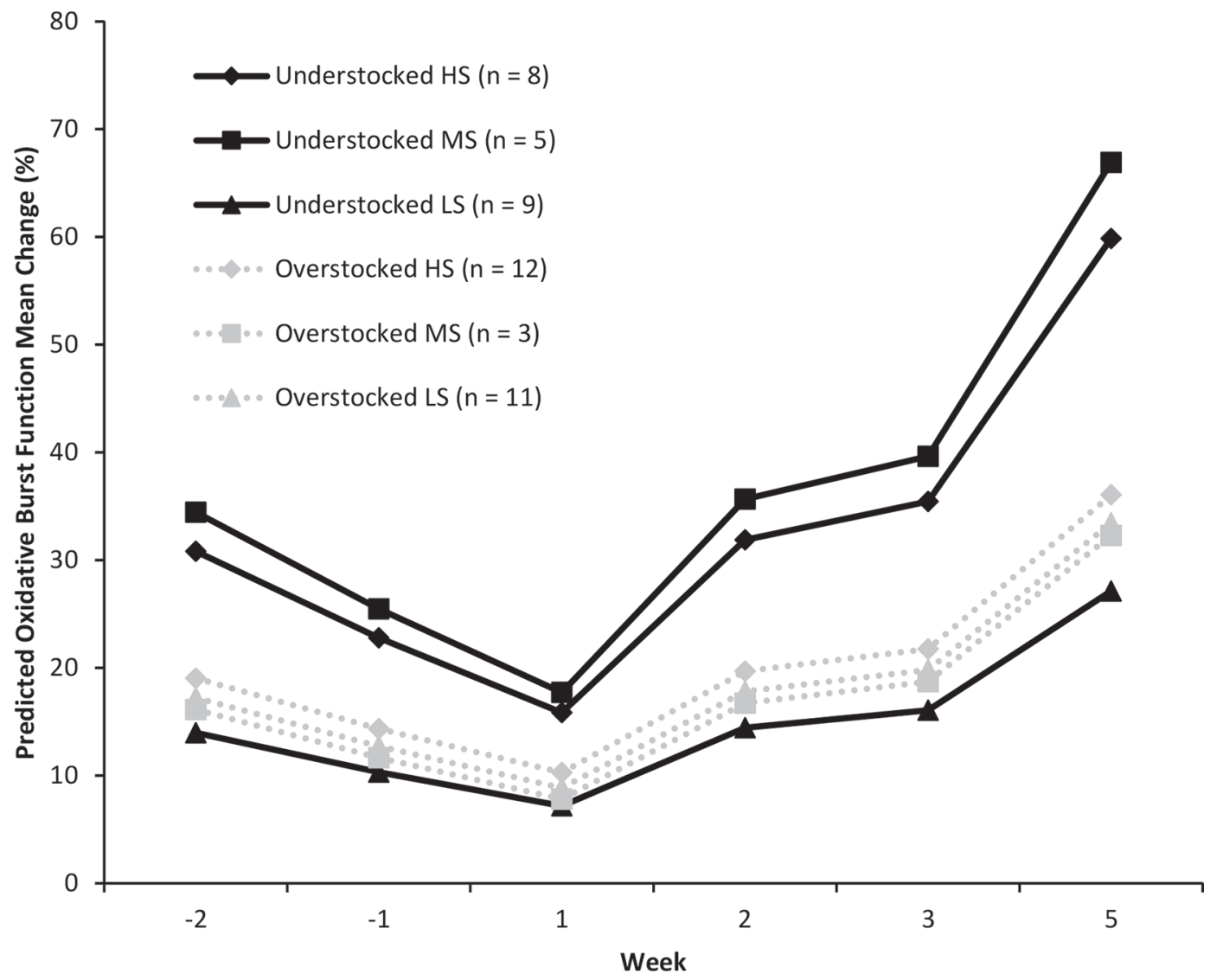

Figure 1. Model-predicted oxidative burst function in cows that were understocked or overstocked for 3 wk before calving. Understocked cows had $90 \mathrm{~cm}$ of feeding space per cow and lying spaces were stocked at $80 \%$ cows to stalls. Overstocked cows had $45 \mathrm{~cm}$ of feeding space per cow and lying spaces were stocked at $120 \%$ cows to stalls. A competition index was calculated for each cow by dividing the number of times the cow displaced another at the feed bunk by the total number of displacements the cow was involved in as either an actor or a reactor. Cows were divided into 3 subgroups based on their competition index: high success (HS; $\geq 0.6$ ), medium success (MS; 0.4 to $<0.6$ ), and low success $(\mathrm{LS} ;<0.4)$. 


\section{Effect of Treatment on Milk Yield}

Daily milk yield was collapsed into weekly averages and compared between groups during the first $5 \mathrm{wk}$ postpartum while cows were enrolled in the experiment. There was no difference in daily milk yield between understocked $(35.6 \pm 1.3 \mathrm{~L} / \mathrm{d})$ and overstocked $(35.2$ $\pm 1.1 \mathrm{~L} / \mathrm{d})$ cows $(P=0.83)$ accounting for parity and week.

\section{DISCUSSION}

The purpose of this study was to investigate whether reducing competition for feeding and lying space alters metabolic health and immune function. Housing prepartum cows at $120 \%$ cows to stalls with $45 \mathrm{~cm}$ of bunk space compared with $80 \%$ cows to stalls with 90 $\mathrm{cm}$ of bunk space produced greater competition at the feed bunk and reduced lying time. Cows exposed to the lower stocking density had modestly improved albumin and calcium concentrations during the peripartum period and tended to have lower liver TAG content at 3 wk postpartum. Within the understocked treatment, cows of higher social rank had higher neutrophil oxidative burst compared with overstocked cows.

Recommendations in the literature state that overcrowding should be avoided in transition pens, stocking at no more than 1:1 cows to stalls, and that pen additions should be limited (Grant and Albright, 2001; Cook and Nordlund, 2004). Nordlund et al. (2006) noted that lactating cattle will generally not fill more than $80 \%$ of 24 -inch $(61 \mathrm{~cm})$ headlocks; therefore, 30 inches $(76 \mathrm{~cm})$ per cow should be offered, and wider late-pregnant cows might benefit from even more space. Although commonly cited, these recommendations are not well supported with controlled experiments (Cook and Nordlund, 2004). Very little peer-reviewed literature has examined metabolic health of transition cows relative to housing environment. Two recent studies with adequate statistical power that examined prepartum housing found no difference in the incidence of retained fetal membranes or metritis or in concentrations of NEFA or BHB with housing strategies intended to reduce social stress (Silva et al. 2013a, 2014).

Cows in the overstocked group spent significantly less time lying per day. Not surprisingly, heifers spent less time lying per day than multiparous cows and participated in a similar number of displacements regardless of which group they were in. Daily rumination time did not differ between groups. We do not know whether increased competition altered DMI among the overstocked cows because we could not measure individual DMI in this facility.
Data reported in other dry cow studies suggest that lying times for dry cows range from 12.3 to $14 \mathrm{~h} / \mathrm{d}$ (Dechamps et al., 1989; Huzzey et al., 2006; Proudfoot et al., 2009). Daily feeding time of nonlactating cows is not well described in the literature but has been reported as means of $86.8 \pm 2.95$ and $230 \mathrm{~min} / \mathrm{d}$ in 2 dry cow experiments (Huzzey et al., 2006, 2012). Based on the extent of crowding in the overstocked group, there would be enough time in the day for cows to perform these behaviors. However, dairy cattle have been described to be allelomimetic, preferring to perform the same activity at the same time as herd mates, including resting, eating, and drinking (Miller and Wood-Gush, 1991). Feeding behavior in particular is highly synchronized in housed cattle, with fresh feed delivery as the primary factor that stimulates eating (von Keyserlingk and Weary, 2010). Therefore, even though the stocking density in the overcrowded pens allowed all cows adequate time in the day to perform desired behaviors, not being able to do so collectively potentially limited the time spent eating and lying for some animals.

Despite the environment being less competitive at the feed bunk and understocked cows having more time to rest, only a few modest metabolic or immunological differences were found in the understocked cows during the transition period. Cows in the understocked group tended to have higher calcium and albumin. In the blood, approximately half of calcium is bound to albumin; therefore, the difference in total calcium may not represent a difference in available calcium. The effect of including albumin in the calcium model seems to support this hypothesis. Albumin is a negative acute-phase protein that decreases during inflammation via reduced hepatic synthesis. Although there was a difference in albumin concentration, there was no accompanying difference in the measured positive acute-phase protein, haptoglobin, as would be expected. It is difficult to assess whether the albumin change is meaningful, which might be clearer if other positive acute-phase proteins such as serum amyloid A had been measured. However, Burke et al. (2010) and Green et al. (2009) found albumin to be slightly but significantly lower through the transition period in cows that were diagnosed with endometritis at 42 DIM. We found a similar magnitude of difference (1-1.5 g/L) between understocked and overstocked cows as was seen between cows that later did or did not have endometritis (Burke et al., 2010). There was no difference between treatment groups in the prevalence of endometritis at wk 5 in the present study; however, the study was not designed to have the statistical power to detect such a difference.

Liver TAG content tended to be lower among understocked cows in the third week after calving. Bobe et al. 
(2004) describes $>5 \%$ TAG content as consistent with moderate fatty liver. At wk $3,14 \%$ of understocked cows and $43 \%$ of overstocked cows had TAG $>5 \%$. However, these proportions were not significantly different, and the study was not powered to detect a difference in the proportion of cows with fatty liver. Other markers of energy status and adaptation to negative energy balance such as NEFA, BHB, glucose, insulin, and IGF-1 were not different between groups, so it is unclear why the mean hepatic content of lipids tended to be higher at wk 3 among overstocked cows considering BCS at enrollment was not a significant covariate in the TAG content models.

We found some indication of differences in metabolism between cows of different social status. Serum insulin and IGF-1 concentrations were significantly lower among cows with a low C_Ind compared with a high C_Ind, and glucose showed a similar tendency. However, there was no interaction between C_Ind and treatment group, indicating that differences were not more pronounced in the overstocked group. It is unknown whether such an interaction would be present in similar stocking density situations of a larger group or unstable population of prepartum cows. In the prepartum period, circulating glucose, insulin, and IGF-1 concentrations are associated with energy status. Huzzey et al. (2012) reported that late-gestation cows of low competitive success had a different physiological profile than high-success cows as indicated by greater NEFA concentrations and a difference in peak insulin response to a glucose tolerance test. The association between lower social status and these metabolites in the present study suggests that energy metabolism was different for these cows, and a larger study would be needed to assess whether this is repeatable and associated with the incidence of disease.

There was no main effect of lying and feeding space allowance on measures of neutrophil function, similar to Silva et al. (2013b), who evaluated the percentage of neutrophils positive for phagocytosis or oxidative burst among a subgroup of 68 Jersey cows housed in a stable housing group with no further additions or a traditional close-up group with weekly additions of animals. When C_Ind category was offered to the oxidative burst model in the present study, a treatment $x$ C_Ind interaction showed that although oxidative burst function was similar between competition categories in the overstocked groups, cows in the understocked group with a moderate or high C_Ind had greater oxidative burst function than low-ranking cows and overstocked cows. Cows in the understocked group with a low competition score did not differ from the overstocked cows, suggesting that the benefit of reduced competition did not extend to them. More generous space allowance only enhanced oxidative burst in more socially dominant (at the feed bunk) animals. Chebel et al. (2016) corroborated this finding in a sample of 94 Jersey cows that were housed in a stable group or with varying stocking density and weekly additions. Animals in the top decile of displacement index had greater intensity of phagocytosis and oxidative burst than animals in the bottom 10th percentile and middle displacement index. Social hierarchy is established through physical and nonphysical interactions, and regrouping forces cows to constantly re-establish this order, intensifying aggressive and submissive behaviors (von Keyserlingk et al., 2008). Assuming that social status of a cow would be unchanged regardless of treatment group, it seems that in a stable group with greater lying and feeding space, cows higher in the social hierarchy were able to extract an advantage from lower competition, yet the space allowances provided in this study were not sufficient to compensate for the effect of lower competitive success at the feed bunk. Chebel et al. (2016) suggested that dominance may be detrimental to cows that spend time asserting their dominance at the feed bunk rather than actually consuming more feed. Understocked cows in the present study spent a greater amount of time lying, and although DMI was not measured, we hypothesize that more dominant cows in the understocked environment could have spent less time defending resources and had improved DMI, which translated into improved immune function. However, the reason for differences in oxidative burst without changes in other measured metabolites is not obvious.

The interaction found between competitive success at the feed bunk and space allowance for neutrophil oxidative burst points to nuances and conditional effects of feed and lying space. Examining metabolic and immune function parameters in relation to social status in a larger study would be worthwhile. Although it would be challenging to study, there may be interactions among the effects of space allowances, social group stability, and competitive success for resources. Whether space allotment could be increased to a level that benefits immune function in all cows regardless of social status or that compensates for low social status is not known. It is possible that regardless of the space allotted, the inherent social hierarchy and its expression by cows would always result in some cows being disadvantaged.

Despite greater competition at the feed bunk and reduced lying time, the expected harmful effects of crowding and competition on metabolic health and innate immune function were mostly not seen. One difference between the overcrowding in this research study and crowding that occurs on commercial dairies is the length of time that cows were exposed. Study subjects were in a zero-competition environment (tiestalls) for 
the far-off dry period before commencing the study and for the 5 wk after calving while they continued to be assessed. Crowding that occurs throughout the far-off, close-up, and fresh periods may have worse effects and elicit metabolic and immune function differences that were not seen in the current experiment. Additionally, the experience of cows in commercial dairy herds reflects more complex and conditional interactions among space allowances, social group and nutritional changes, and other variables such that greater space allowances might be relevant in the field.

\section{CONCLUSIONS}

A noncompetitive housing strategy of $80 \%$ cows to stalls and $90 \mathrm{~cm}$ of bunk space modestly improved albumin and calcium concentrations during the peripartum period and improved the oxidative burst function of blood neutrophils among cows with higher social status compared with cows with low social status in the understocked group. The housing strategy failed to improve other markers of metabolic health. On average, crowding in a small, stable group through the closeup dry period without crowding or social instability in the postpartum period did not negatively affect the metabolic health and immune function of cows. These results do not refute the importance of access to feeding and lying space but rather indicate that metabolic and reproductive health is more complex than can be explained solely by exposure to what are thought to be best management practices for space allowances.

\section{ACKNOWLEDGMENTS}

The authors thank the Ontario Ministry of Agriculture, Food and Rural Affairs (Guelph, ON, Canada) and the National Science and Engineering Research Council (Ottawa, ON, Canada) for funding. We are grateful to Laura Wright and the staff at the Elora Dairy Research Centre (University of Guelph, Guelph, ON, Canada), Mary Ellen Clark (Department of Pathobiology, University of Guelph) for technical assistance, and Juan Loor of the Mammalian NutriPhysioGenomics laboratory (Department of Animal Sciences, University of Illinois, Urbana) for assistance with liver biopsy analysis.

\section{REFERENCES}

Bobe, G., J. W. Young, and D. C. Beitz. 2004. Invited review: Pathology, etiology, prevention, and treatment of fatty liver in dairy cows. J. Dairy Sci. 87:3105-3124.

Burke, C. R., S. Meier, S. McDougall, C. Compton, M. Mitchell, and J. R. Roche. 2010. Relationships between endometritis and metabolic state during the transition period in pasture-grazed dairy cows. J. Dairy Sci. 93:5363-5373.
Chebel, R. C., P. R. Silva, M. I. Endres, M. A. Ballou, and K. L. Luchterhand. 2016. Social stressors and their effects on immunity and health of periparturient dairy cow. J. Dairy Sci. 99:3217-3228.

Cook, N. B., and K. V. Nordlund. 2004. Behavioral needs of the transition cow and considerations for special needs facility design. Vet. Clin. North Am. Food Anim. Pract. 20:495-520.

De Koster, J. D., and G. Opsomer. 2013. Insulin resistance in dairy cows. Vet. Clin. North Am. Food Anim. Pract. 29:299-322.

Dechamps, P., B. Nicks, B. Canart, M. Gielen, and L. Istasse. 1989. A note on resting behaviour of cows before and after calving in two different housing systems. Appl. Anim. Behav. Sci. 23:99-105.

DFC-NFACC. 2009. DFC-NFACC (Dairy Farmers of Canada and the National Farm Animal Care Council) Code of Practices for the Care and Handling of Dairy Cattle. Dairy Farmers of Canada, Ottawa, Ontario, Canada.

Dubuc, J., T. F. Duffield, K. E. Leslie, J. S. Walton, and S. J. LeBlanc. 2010. Definitions and diagnosis of postpartum endometritis in dairy cows. J. Dairy Sci. 93:5225-5233.

Ferguson, J. D., D. T. Galligan, and N. Thomsen. 1994. Principal descriptors of body condition score in Holstein cows. J. Dairy Sci. 77:2695-2703.

Galindo, F., and D. M. Broom. 2000. The relationships between social behaviour of dairy cows and the occurrence of lameness in three herds. Res. Vet. Sci. 69:75-79.

Galvão, K. N., M. J. Flaminio, S. B. Brittin, R. Sper, M. Fraga, L. Caixeta, A. Ricci, C. L. Guard, W. R. Butler, and R. O. Gilbert. 2010. Association between uterine disease and indicators of neutrophil and systemic energy status in lactating Holstein cows. J. Dairy Sci. 93:2926-2937.

Goff, J. P., and R. L. Horst. 1997. Physiological changes at parturition and their relationship to metabolic disorders. J. Dairy Sci. $80: 1260-1268$.

Grant, R. J., and J. L. Albright. 2001. Effect of animal grouping on feeding behavior and intake of dairy cattle. J. Dairy Sci. 84:E156E163.

Green, M. P., A. M. Ledgard, M. C. Berg, A. J. Peterson, and P. J. Back. 2009. Prevalence and identification of systemic markers of sub-clinical endometritis in postpartum dairy cows. Proc. N. Z. Soc. Anim. Prod. 69:37-42.

Grummer, R. R. 1993. Etiology of lipid-related metabolic disorders in periparturient dairy cows. J. Dairy Sci. 76:3882-3896.

Hammon, D. S., I. M. Evjen, T. R. Dhiman, J. P. Goff, and J. L. Walters. 2006. Neutrophil function and energy status in Holstein cows with uterine health disorders. Vet. Immunol. Immunopathol. $113: 21-29$.

Huzzey, J. M., T. J. DeVries, P. Valois, and M. A. von Keyserlingk. 2006. Stocking density and feed barrier design affect the feeding and social behavior of dairy cattle. J. Dairy Sci. 89:126-133.

Huzzey, J. M., D. V. Nydam, R. J. Grant, and T. R. Overton. 2012. The effects of overstocking Holstein dairy cattle during the dry period on cortisol secretion and energy metabolism. J. Dairy Sci. 95:4421-4433.

Huzzey, J. M., D. M. Veira, D. M. Weary, and M. A. von Keyserlingk. 2007. Prepartum behavior and dry matter intake identify dairy cows at risk for metritis. J. Dairy Sci. 90:3220-3233.

Kehrli, M. E., Jr., B. J. Nonnecke, and J. A. Roth. 1989. Alterations in bovine neutrophil function during the periparturient period. Am. J. Vet. Res. 50:207-214.

Kim, I. H., K. J. Na, and M. P. Yang. 2005. Immune responses during the peripartum period in dairy cows with postpartum endometritis. J. Reprod. Dev. 51:757-764.

Ledgerwood, D. N., C. Winckler, and C. B. Tucker. 2010. Evaluation of data loggers, sampling intervals, and editing techniques for measuring the lying behavior of dairy cattle. J. Dairy Sci. 93:5129-5139.

Matteo, G., C. Mauro, and M. Massimo. 2009. Cows response to glucose tolerance test (GTT) and periparturient diseases: Preliminary study. J. Dairy. Sci. 92(E-Suppl. 1):385. (Abstr.)

Miller, K., and D. G. M. Wood-Gush. 1991. Some effects of housing on the social behaviour of dairy cows. Anim. Sci. 53:271-278. 
Mølgaard, L., B. M. Damgaard, V. Bjerre-Harpøth, and M. S. Herskin. 2012. Effects of percutaneous needle liver biopsy on dairy cow behaviour. Res. Vet. Sci. 93:1248-1254.

Nordlund, K., N. Cook, and G. Oetzel. 2006. Commingling dairy cows: Pen moves, stocking density and health. Pages 36-42 in Proc. American Association of Bovine Practitioners 39th Mtg., St. Paul. MN.

Proudfoot, K. L., D. M. Veira, D. M. Weary, and M. A. von Keyserlingk. 2009. Competition at the feed bunk changes the feeding, standing, and social behavior of transition dairy cows. J. Dairy Sci. 92:3116-3123.

Scalia, D., N. Lacetera, U. Bernabucci, K. Demeyere, L. Duchateau, and C. Burvenich. 2006. In vitro effects of nonesterified fatty acids on bovine neutrophils oxidative burst and viability. J. Dairy Sci. $89: 147-154$.

Schirmann, K., M. A. von Keyserlingk, D. M. Weary, D. M. Veira, and W. Heuwieser. 2009. Technical note: Validation of a system for monitoring rumination in dairy cows. J. Dairy Sci. 92:6052-6055.

Sheldon, I. M., G. S. Lewis, S. LeBlanc, and R. O. Gilbert. 2006. Defining postpartum uterine disease in cattle. Theriogenology 65:1516-1530.

Sheldon, I. M., D. E. Noakes, A. N. Rycroft, D. U. Pfeiffer, and H. Dobson. 2002. Influence of uterine bacterial contamination after parturition on ovarian dominant follicle selection and follicle growth and function. Reproduction 123:837-845.
Silva, P. R., A. R. Dresch, K. S. Machado, J. G. Moraes, K. LobeckLuchterhand, T. K. Nishimura, M. A. Ferreira, M. I. Endres, and R. C. Chebel. 2014. Prepartum stocking density: Effects on metabolic, health, reproductive, and productive responses. J. Dairy Sci 97:5521-5532.

Silva, P. R., J. G. Moraes, L. G. Mendonca, A. A. Scanavez, G. Nakagawa, M. A. Ballou, B. Walcheck, D. Haines, M. I. Endres, and R. C. Chebel. 2013a. Effects of weekly regrouping of prepartum dairy cows on innate immune response and antibody concentration. J. Dairy Sci. 96:7649-7657.

Silva, P. R., J. G. Moraes, L. G. Mendonca, A. A. Scanavez, G. Nakagawa, J. Fetrow, M. I. Endres, and R. C. Chebel. 2013b. Effects of weekly regrouping of prepartum dairy cows on metabolic, health, reproductive, and productive parameters. J. Dairy Sci 96:4436-4446.

UBC AWP (University of British Columbia Animal Welfare Program) 2013. UBC Animal Welfare Program: SOP - HOBO data loggers. Accessed Dec. 12, 2013. http://awp.landfood.ubc.ca/files/2013/ 11/SOP-HOBO-Datalogger-november-2013.pdf.

von Keyserlingk, M. A., D. Olenick, and D. M. Weary. 2008. Acute behavioral effects of regrouping dairy cows. J. Dairy Sci. 91:10111016.

von Keyserlingk, M. A., and D. M. Weary. 2010. Review: Feeding behaviour of dairy cattle: Measures and applications. Can. J. Anim. Sci. 90:303-309. 